\title{
Perkembangan Gunung Agung, Kebencanaan, dan Persoalan Pengungsi
}

\author{
Dewa Made Indra \\ Kepala Pelaksana BPBD Provinsi Bali
}

\begin{abstract}
Mount Agung in Karangasem Regency is one of the volcanoes in Bali. This mountain is in the path of the Pacific Ring of Fire. Towards the end of 2017 and the beginning of 2018, the mountain which is highly purified by the Balinese Hindu community are erupted. Although the eruptions were not as large as in 1963, thousands of people during 2017 were displaced not only around Karangasem Regency but also in some others in Bali. This qualitative study found that, until the eruption in 2017 and 2018, Mount Agung is said to be still in a state of disaster. For that reason, there are still residents who reside less than 4 kilometers from the peak of Mount Agung lived in refugee camps. Nevertheless, in general the problem of evacuation can be said to have been going well.
\end{abstract}

Keywords: volcano, eruption, refugee, evacuation.

\section{PENDAHULUAN}

Gunung Agung merupakan gunung tertinggi di Pulau Bali. Gunung ini terletak di Kabupaten Karangasem dan merupakan gunung api aktif tipe A. Menurut sejarah letusannya gunung berapi tipe $A$ merupakan gunung berapi yang pernah mengalami erupsi sekurang-kurangnya satu kali setelah tahun 1600 M. Banyak dari gunung berapi tipe A yang masih aktif yang menunjukkan tanda-tanda gejala erupsi dan salah satunya adalah Gunung Agung.

Posisi Geografis Gunung Agung terletak pada posisi 08²0' 30' Lintang Selatan dan 115030' 30' Bujur Timur dengan ketinggian 3.014 meter di atas permukaan laut. Gunung Agung tercatat telah mengalami 4 kali letusan, dengan letusan pertama tahun 1808, kemudian di tahun 1821, lalu tahun 1843 dan terakhir pada tahun 1963. Letusan terakhir ini terjadi setelah 120 tahun Gunung Agung mengalami fase tidur yang waktunya panjang. 
Kabupaten yang berada di sekitar Gunung Agung adalah Kabupaten Klungkung, Kabupaten Bangli, Kabupaten Buleleng, dan Kabupaten Gianyar. Sedangkan Kabupaten Karangasem sendiri sebagai lokasi keberadaan Gunung Agung memiliki total 78 desa. Sesuai pemetaan dari Pusat Vulkanologi Mitigasi Bencana Geologi (PVMBG) dan Kementerian Energi Sumber Daya Mineral (ESDM) Republik Indonesia, bahwa ada 28 desa yang berada dalam Kawasan Rawan Bencana (KRB) Erupsi Gunung Agung dalam radius 6-12 kilometer dari puncak kawah Gunung Agung dengan rincian, sebanyak 6 Desa KRB 3, lalu 16 Desa KRB 2 dan 6 desa KRB 1 . Sedangkan untuk 56 desa lainnya di Kabupaten Karangasem adalah berada di luar KRB artinya radius aman.

Nama dari ke-28 desa yang masuk dalam Kawasan Rawan Bencana (KRB) Gunung Agung adalah: Desa Besakih, Desa Sebudi, Desa Jungutan, Desa Buana Giri, Desa Ban, Desa Dukuh, Desa Menanga, Desa Pempatan, Desa Muncan, Desa Peringsari, Desa Selat, Desa Amertabuana, Desa Duda Utara, Desa Bebandem, Desa Ababi, Desa Datah, Desa Nawakerti, Desa Pidpid, Desa Baturinggit, Desa Kubu, Desa Sukadana, Desa Tulamben, Desa Rendang, Desa Duda, Desa Duda Timur, Desa Sibetan, Desa Macang, dan Desa Budakeling. Untuk diketahui bahwa para Kepala Desa dalam KRB ini telah membentuk organisai Pasebaya yakni Pasemetonan Jaga Baya yang bertugas untuk memberikan sosialisasi, edukasi, dan sekaligus membantu petugas melakukan proses evakuasi warga agar tidak melakukan aktivitas pada radius bahaya Gunung Agung ini bilamana terjadi letusan.

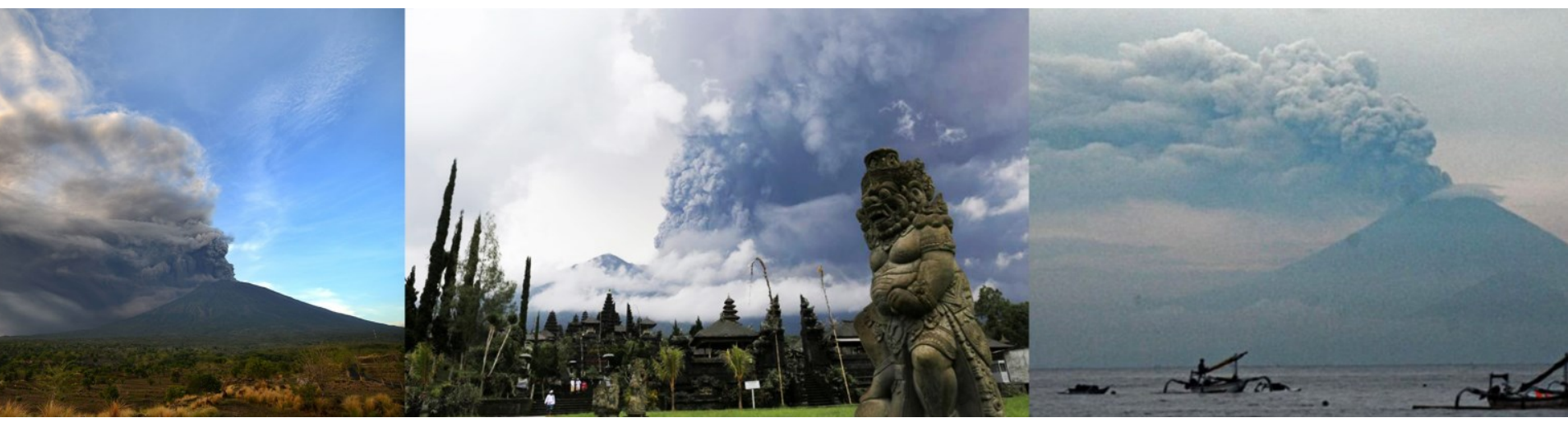




\section{PEMBAHASAN}

Sesuai laporan aktivitas gunung api yang dikeluarkan oleh petugas Pos Pengamatan Gunungapi Agung, KESDM, Badan Geologi, PVMBG dalam situs resminya: https: //magma.vsi.esdm.go.id/ yang berlokasi di Desa Rendang Kecamatan Rendang, Kabupaten Karangasem, bahwa pada periode pengamatan Selasa 30 Januari 2018 pukul 12.00 Wita sampai pukul 18.00 wita, Gunung Api Gunung Agung secara visual berkabut 0-III dengan asap kawah tidak teramati. Cuaca di sekitar gunung berawan, mendung, dan hujan. Angin bertiup lemah hingga sedang ke arah timur. Suhu udara 26-29 ${ }^{\circ} \mathrm{C}$ dan kelembaban udara 67-78\%. Bahkan volume curah hujan tidak tercatat.

Pada catatan aktivitas kegempaan, disampaikan juga bahwa telah terjadi embusan sejumlah 2, Amplitudo: 10-12 mm, Durasi: 45-50 detik. Kemudian Vulkanik Dangkal sejumlah 3, Amplitudo: 10-11 mm, Durasi: 30-32 detik dan terjadi Tektonik Jauh sejumlah: 1, Amplitudo: 20 mm, S-P: 14 detik, Durasi: 70 detik. Demikian juga masih terjadi aktivitas Tremor Menerus (Microtremor) terekam dengan amplitudo 1-3 $\mathrm{mm}$ (dominan $2 \mathrm{~mm}$ ).

Dari situasi dan kondisi seperti itu, maka kesimpulannya adalah bahwa Tingkat Aktivitas Gunung Agung masih berada pada Level IV (Awas). Untuk diketahui Status Gunung Agung pada Level IV (Awas) ini sudah terjadi sejak tanggal 27 November 2017 lalu dengan dikeluarkannya Surat Badan Geologi, Kementerian Energi dan Sumber Daya Mineral RI Nomor: 2043/45/BGL.V/2017 tentang peningkatan Status Gunung Agung Level III (Siaga) ke level IV (Awas). Karena kondisi Gunung Agung ini bersifat dinamis, maka pada beberapa kali perubahan peringatan dini serta arahan Petugas Pos Pengamatan Aktivitas Gunung Agung di Desa Rendang, yang disampaikan 


\section{4 | Dewa Made Indra}

melalui aplikasi Magma Var Indonesia, disampaikan bahwa sejak tanggal 4 Januari 2018 lalu, radius terdampak bahaya aktivitas Gunung Agung mengecil dari $8 \mathrm{~km}$ sektoral $10 \mathrm{~km}$ menjadi $6 \mathrm{~km}$ tanpa sektoral. Artinya, berubah pula jumlah desa serta dusunnya yang berada pada zona KRB, dan hal itu direkomendasikan sebagai berikut.

1. Masyarakat di sekitar Gunung Agung dan pendaki/pengunjung/wisatawan agar tidak berada, tidak melakukan pendakian dan tidak melakukan aktivitas apapun di dalam Zona Perkiraan Bahaya yaitu di dalam area kawah Gunung Agung dan diseluruh area di dalam radius 6 km dari Kawah Puncak Gunung Agung. Zona Perkiraan Bahaya sifatnya dinamis dan terus dievaluasi dan dapat diubah sewaktu-waktu mengikuti perkembangan data pengamatan aktivitas Gunung Agung yang paling aktual/terbaru. Di dalam radius $6 \mathrm{~km}$ terdapat 12 desa yang harus dievakuasi, yaitu Desa Nawakerti, Desa Jungutan, Desa Buana Giri, Desa Sebudi, Desa Besakih, Desa Datah, Desa Pempatan, Desa Tulamben, Desa Dukuh, Desa Kubu, Desa Baturinggit, dan Desa Ban.

2. Masyarakat yang bermukim dan beraktivitas di sekitar aliran sungai-sungai yang berhulu di Gunung Agung agar mewaspadai dan mengantisipasi potensi ancaman bahaya sekunder berupa lahar hujan terutama pada musim penghujan seperti saat ini.

3. Status Level IV (Awas) hanya berlaku pada Zona Perkiraan Bahaya seperti tersebut di atas. Masyarakat yang berada di luar zona bahaya dapat beraktivitas seperti biasa namun agar tetap menjaga kewaspadaan.

Lalu untuk kesekian kalinya Gunung Agung kembali erupsi dengan ketinggian kolom erupsi sekitar 2.000 hingga 2.500 
meter di atas puncak kawah, yakni pada hari Senin 15 januari 2018 pukul 07.23 WITA. Erupsi kali ini disertasi asap dan abu vulkanik berwarna kelabu dengan tekanan sedang, intensitas sedang dan condong ke arah timur laut. PVMBG melaporkan erupsi hanya sesaat dan tidak menerus karena gempa letusannya hanya sesaat pada pukul 07.23 Wita. Aktivitas vulkanik masih cukup tinggi yang ditandai dengan kegempaan dan tremor menerus. Status Awas (level IV) dengan rekomendasi daerah berbahaya adalah masih tetap pada radius 6 kilometer dari puncak kawah dan arahannya adalah tidak boleh ada aktivitas masyarakat dalam bentuk apapun di dalam radius 6 kilometer, sedangkan di luar radius 6 kilometer, kondisinya aman. Artinya, hanya sekitar 2\% dari total wilayah pulau Bali yang berada pada perkiraan zona bahaya aktivitas Gunung Agung ini.

Sesuai Standar Operasi Prosedur (SOP) dalam upaya peningkatan keselamatan perhubungan udara maka PVMBG juga telah mengeluarkan VONA (Volcano Observatory Notice for Aviation) dengan kode warna ORANGE pascaerupsi ini dan sebaran abu vulkanik hanya terjadi di sekitar Gunung Agung. Abu vulkanik tidak ada yang mengarah ke Bandar Udara I Gusti Ngurah Rai Bali. Kondisi Bandar Internasional I Gusti Ngurah Rai dan Bandara Internasional Lombok aman dan beroperasi normal.

Hujan abu vulkanik tipis dilaporkan oleh beberapa pos pengamatan di Pasebaya jatuh di beberapa desa seperti di Desa Kesimpar, Desa Datah Kecamatan Abang Kabupaten Karangasem. Aktivitas masyarakat tetap berjalan normal. Masyarakat melihat erupsi Gunung Agung juga tidak panik. Sosialisasi yang terus diberikan kepada masyarakat mengenai potensi dan antisipasi erupsi Gunung Agung menyebabkan tingkat kesiapsiagaan 
masyarakat meningkat. Pengalaman penanganan erupsi selama November 2017 lalu telah memberikan pemahaman yang lebih baik sehingga masyarakat lebih siap menghadapi erupsi.

Sementara itu, akibat erupsi Gunung Agung dan menindaklanjuti arahan serta rekomendasi PVMBG, maka ada pengungsian 12 warga desa dalam radius $6 \mathrm{~km}$ tadi. Jumlah pengungsi hingga pukul 18.00 wita tanggal 30 Januari 2018 adalah sebanyak 23.179 jiwa yang berada di 189 titik pengungsian, sebarannya berada di Kabupaten Karangasem, Buleleng, Gianyar, Klungkung dan Bangli.

BNPB dan BPBD serta unsur terkait terus memberikan pendampingan dan bantuan kepada Pemerintah Daerah Kabupaten yang menerima pengungsi maupun Posko Tanggap Darurat Gunung Agung di Tanah Ampo serta khususnya kepada masyarakat yang terdampak erupsi Gunung Agung, berupa logistik beras, permakanan, lauk pauk, kesehatan, pendidikan, hiburan serta peralatan lain yang dibutuhkan di tempat pengungsian. Kegiatan lainnya adalah melakukan evakuasi dan pemeliharaan hewan ternak para pengungsi.

\section{PENUTUP}

Masih ada beberapa permasalahan dalam penanganan pengungsi seperti aktivasi posko belum berjalan normal, distribusi logistik ke pos pengungsian belum lancar dan sebagian lainnya. Atas dasar semua permasalahan ini, langkah cepat koordinasi, komunikasi dan intervensi pemerintah kabupaten, pemerintah provinsi maupun pusat melalui BPBD, BNPB dan Kementerian terus dilakukan termasuk oleh swasta serta berbagai pihak yang membantu.

Saat tulisan ini dibuat, Pemerintah masih terus mengimbau masyarakat sekitar Gunung Agung khususnya dalam radius bahaya $6 \mathrm{~km}$ dari puncak kawah untuk selalu meningkatkan kewaspadaan menghadapi dampak aktivitas Gunung Agung ini sedangkan Masyarakat Bali umumnya tetap melaksanakan kegiatan normal seperti biasa karena dampaknya hanya pada perkiraan $2 \%$ saja sekitar Gunung Agung. 


\section{REFERENSI}

https: //magma.vsi.esdm.go.id/.

Kementerian Energi Sumber Daya Mineral (ESDM) Republik Indonesia. 2017. Pemetaan Pusat Vulkanologi Mitigasi Bencana Geologi (PVMBG), terhadap Kawasan Rawan Bencana (KRB) Erupsi Gunung Agung.

Surat Badan Geologi, Kementerian Energi dan Sumber Daya Mineral RI Nomor: 2043/45/BGL.V/2017 tentang Peningkatan Status Gunung Agung Level III (Siaga) ke level IV (Awas). 